\title{
Life Cycle Assessment of Wastewater Treatment Plants in Ireland
}

\author{
Greg McNamara*1, Lorna Fitzsimons' ${ }^{2}$ Matthew Horrigan ${ }^{3}$, Thomas Phelan ${ }^{4}$, \\ Yan Delaure $^{5}$, Brian Corcoran ${ }^{6}$, Edelle Doherty $^{7}$, Eoghan Clifford $^{8}$ \\ ${ }^{1}$ School of Mechanical Engineering, Dublin City University, Glasnevin, Dublin 9, Ireland \\ e-mail: greg.mcnamara5@mail.dcu.ie \\ ${ }^{2}$ School of Mechanical Engineering, Dublin City University, Glasnevin, Dublin 9, Ireland \\ e-mail: lorna.fitzsimons@dcu.ie \\ ${ }^{3}$ School of Mechanical Engineering, Dublin City University, Glasnevin, Dublin 9, Ireland \\ e-mail: matthewhorrigan@gmail.com \\ ${ }^{4}$ School of Mechanical Engineering, Dublin City University, Glasnevin, Dublin 9, Ireland \\ e-mail: thomas.phelan4@mail.dcu.ie \\ ${ }^{5}$ School of Mechanical Engineering, Dublin City University, Glasnevin, Dublin 9, Ireland \\ e-mail: yan.delaure@dcu.ie \\ ${ }^{6}$ School of Mechanical Engineering, Dublin City University, Glasnevin, Dublin 9, Ireland \\ e-mail: brian.corcoran@dcu.ie \\ ${ }^{7}$ Civil Engineering, College of Engineering and Informatics, National University of Ireland Galway \\ University Road, Galway, Ireland \\ e-mail: edelledoherty@gmail.com \\ ${ }^{8}$ Civil Engineering, College of Engineering and Informatics, National University of Ireland Galway \\ University Road, Galway, Ireland \\ e-mail: eoghan.clifford@ nuigalway.ie
}

\begin{abstract}
The Urban Wastewater Treatment Directive 91/271/EEC introduced a series of measures for the purpose of protecting the environment from the adverse effects of effluent discharge from wastewater treatment plants. There are environmental costs associated with attaining the required level of water quality set out in the directive such as greenhouse gas emissions due to energy production, and ecotoxicity from sludge application to land. The goal of this study is to assess the environmental costs in an Irish context, focusing specifically on the effects of variation in scale and discharge limitation. Life cycle assessment is the analytical tool used to evaluate the environmental impact. The life cycle impact assessment methodology developed by the Centre of Environmental Science, Leiden University (2010) has been adopted and implemented using GaBi 6.0 life cycle assessment software. Two plants of varying size and location were chosen for the study. The study found that energy consumption and sludge application to land are the largest contributors to the overall environmental impact associated with the treatment process at both plants. Economies of scale were observed in energy usage during secondary aeration.
\end{abstract}

\section{KEYWORDS}

Wastewater treatment, Life cycle assessment, Energy, Sludge disposal, Anaerobic digestion, Discharge limitations.

\footnotetext{
* Corresponding author
} 


\section{INTRODUCTION}

On the $21^{\text {st }}$ of May 1991 the then European Economic Community (EEC) issued the 91/271/EEC Urban Wastewater Treatment Directive (UWWTD) that would set in motion a series of reforms to protect the environment from the adverse effects of effluent being discharged from Wastewater Treatment Plants (WWTPs) [1]. The directive made recommendations on the collection, treatment, and discharge of urban waste water. One of the key recommendations made in the directive is that WWTPs serving agglomerations greater than $2,000 \mathrm{PE}^{\dagger}$ discharging final effluent into freshwater and estuaries, and all other agglomerations greater than 10,000 PE are to employ secondary treatment ${ }^{\ddagger}$. This requirement presented local and national authorities with the challenge of firstly assessing the state of their respective sewage systems, before bringing standards to required levels.

In Ireland it is the responsibility of the Environmental Protection Agency (EPA) to enforce the measures outlined in 91/271/EEC. In 2013 the EPA initiated a research project to benchmark the energy and resource efficiency of WWTPs in Ireland. The project involved four different approaches: development of a benchmarking tool, process auditing and optimization, exergy analysis and environmental performance assessment. It is the findings from the latter of these four approaches that is the subject of this study.

The advancement of environmental awareness at both societal and policy-making level over the last two decades has brought with it the need for appropriate tools to analyse products and systems for sustainability and environmental impact. A range of tools have been developed for this purpose such as:

- Environmental Risk Assessment (ERA) [3];

- Environmental Impact Assessment (EIA);

- Ecological footprint [4];

- Exergy Analysis (EA) [5].

It should be noted that the application of exergy analysis to assess environmental impact of a product or system is a relatively new concept and is currently the subject of much debate between those that advocate its use in this context [6], and those who do not [7]. Life Cycle Assessment (LCA) is an analytical tool that allows for a holistic approach to assessing the environmental performance of a product or system from cradle to grave [8]. It has been widely accepted as a decision support tool for government bodies, environmental authorities, and areas of the private sector [9]. The use of LCA is particularly suited to WWTP analyses due to the nature of the relationship between a plant's technosphere and the surrounding ecosphere. Indeed, there has already been a variety of LCA studies carried out on WWTPs, each with their own unique set of objectives, but with the common underlying theme of seeking to quantitatively and qualitatively assess environmental impact.

The application of LCA to a wastewater treatment plant or system was first reported in The Netherlands in 1997. The study carried out by Roeleveld et al. [10] examined the environmental sustainability of wastewater treatment. The study concluded that improvements in the environmental performance of wastewater treatment should focus on minimizing effluent discharge pollutants, and sludge production. Since then, there have been over forty studies published in peer reviewed journals [11]. Much of the earlier

\footnotetext{
${ }^{\dagger} 1 \mathrm{PE}$ (person equivalent) is estimated to be $0.2 \mathrm{~m}^{3}$ of waste water influent and $60 \mathrm{~g}$ of BOD (biological oxygen demand) [2]

\$ "Secondary treatment means treatment of urban waste water by a process generally involving biological treatment with a secondary settlement."
} 
work that was carried out involved assessing the environmental impact of variations in system parameters such as:

- System configuration [12];

- System boundaries and scale [13];

- Structural changes [14];

- Competing technologies for large [15] and small scale plants [16].

Other LCA studies examined wastewater reclamation and reuse alternatives [17].

As the body of work in this area increased some common findings began to emerge. Firstly, the environmental loading associated with energy production for use in the treatment process was found to be one of the main contributors to the overall environmental profile of treatment plants and systems [16], with particular emphasis on global impact categories such as global warming and acidification. This is contrary to the findings in the earlier work by Roeleveld et al. [18] who concluded that electricity use had a negligible impact. However, the results of the study were normalised with Dutch normalization factors that output the electricity use as a percentage of the overall electricity use of The Netherlands. It is not a surprise that the environmental impact from energy use can vary between studies. The magnitude of impact is not only dependant on the amount of energy used, but also on the way the energy is generated. For example, the impact from electricity generation in Norway where over $90 \%$ is hydro-electric power will be much less than that of Italy where over $60 \%$ of electricity is generated from fossil fuels [19].

The second significant finding was the impact resulting from sludge disposal. Much like the impact from energy generation, it is the mode of sludge disposal that dictates both the magnitude and the type of impact incurred. Traditionally, methods of sludge disposal in Europe have been either by application to agricultural farmland, incineration, or by landfill. In relation to the latter, the EU Directive on the landfill of waste (1991/31/EEC) recommends a reduction in the quantities of sewage sludge going to landfills [20], and in some countries such as Sweden the practice has been banned completely since 2005 [21]. The LCA study carried out by Pasqualino et al. [22] that examined several sludge disposal options concluded that land fill was the worst scenario. This finding was echoed by Houillon and Jolliet [23] who also include agricultural application as one of the least desirable methods of sludge disposal from a global warming perspective, and claim that incineration in cement kilns is preferable. Conversely, Lundin et al. [24] expanded the impact assessment of sludge disposal options to include more impact categories than just global warming and found that incineration had environmental restrictions. The debate on sludge disposal is ongoing.

Quite often the metric used to assess the performance of a WWTP is the percentage reduction of influent pollutants such as:

- Biochemical Oxygen Demand (BOD);

- Chemical Oxygen Demand (COD);

- Total Suspended Solids (TSS);

- Total Nitrogen (TN);

- Total Phosphorus (TP).

While control of these parameters is necessary for compliance with the regulations, it affects only eutrophication and aquatic toxicity, and there are many other environmental factors involved that must be taken into account such as global warming resulting from energy production and toxicity resulting from sludge disposal. In more recent times there has been a paradigm shift from considering not only water quality and human health, but also energy and resource recovery during wastewater treatment [11]. A common finding throughout many of the published LCA studies of wastewater treatment plants and 
systems is that there are trade-offs, where reducing the load in one impact category increases the loading in another.

This paper seeks to further expand the knowledge of WWTP analysis by examining the environmental loadings of two WWTPs in Ireland and add to the body of work that has been carried out around the rest of the Europe. To the best of the author's knowledge, this is the first study of this type on the island of Ireland.

\section{GOAL AND SCOPE DEFINITION}

This study is part of a larger project that aims to assess the energy and resource efficiency of WWTPs in Ireland. The main goal of the LCA component of the project is to quantify the environmental loading that results from reaching the effluent quality standards set out in 91/271/EEC. The specific goal of this paper is to assess the environmental costs or gains associated with variations in plant size and location. It has been reported in previous studies by Tillman et al. [12] and Lundin et al. [13] that there are economies of scale to be achieved in terms of environmental impact, however, this claim has never been investigated from an Irish perspective. The variation in plant location focuses mainly on the effects of differences in discharge limitations.

\section{Functional unit}

The choice of functional unit is one of the most critical aspects of an LCA. Baumann and Tillman [8] define the functional unit as corresponding to a reference flow to which all other flows of a system are related. There is some variance of opinion in the literature as to what the most suitable functional unit for this type of study should be: $\mathrm{m}^{3}$ of influent, PE or volume of sludge produced. Volume of treated wastewater per unit time has been suggested by Suh and Rousseaux [25] to be the most appropriate choice as it is based on realistic data. However, Corominas et al. [11] argue that this is not always representative, because it may not give a true indication of the pollutant removal efficiency of a WWTP. Volume of sludge produced has also been suggested [26], although it could be argued that this metric is secondary to the primary function of a WWTP. Population equivalence has been chosen as the function unit by several LCA practitioners $[12,13,16]$, the rationale being that it allows comparisons between plants. However, care must be taken when defining PE as there are two quantities being referred to: volume of influent and mass of organic loading. In this study PE refers to the hydraulic definition of $0.2 \mathrm{~m}^{3}$ of wastewater.

\section{Boundaries}

It has been documented by other LCA practitioners that the construction phase of a WWTP's life cycle is negligible compared to the operation and maintenance phase [12, 13], and as such has been omitted from the analysis. The delivery of influent has not been included in the analysis as delivery systems can vary, thus leading to unfair comparisons of plant efficiency, and therefore the "gate-to-grave" practice has been adopted for the delivery of the influent, whereby the "gate" is deemed to begin where the influent physically enters the WWTP domain. Many LCA studies extend the boundaries of their systems to include the production of mineral fertilizers so as to include nitrogen and phosphorus in the sludge applied to land as avoided products [27, 28]. However, in a study carried out by Renou et al. [29], it is stated that mineral fertilizers are spread on growing crops, and that due to safety concerns sludge is applied to the land before crop growth. Therefore, the sludge cannot be deemed to have the same fertilizing effect. Consequently, nitrogen and phosphorous in sludge outputs have not been included as avoided products. 


\section{PLANT DESCRIPTIONS}

Plant A is the largest and most sophisticated of the two plants under study. It has a design capacity of $186,000 \mathrm{PE}$ and a dry weather flow of $35,000 \mathrm{~m}^{3} /$ day. The plant is situated on the coast and releases its final effluent through a long sea outfall where the waters are deemed to be non-sensitive, thus avoiding the need for nutrient reduction. The SCADA system used at the plant is bespoke and state of the art. All aspects of process control take place at the hub of the SCADA system. Figure 1 shows the treated influent flow line for the plant.

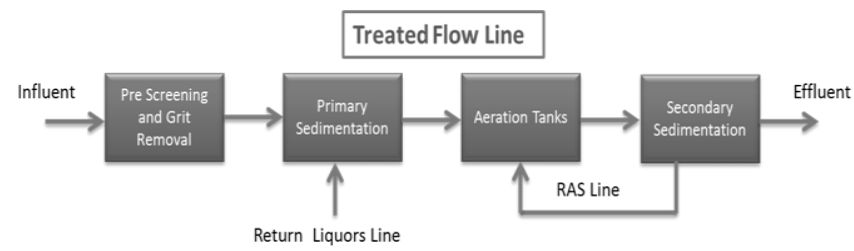

Figure 1. Plant A treated influent flow line

The sludge line is as shown in Figure 2. Primary and secondary sludge go through a series of dewatering and thickening processes, and are then mixed prior to being sent to anaerobic digesters. The sludge is brought to $22 \%$ solids concentration before being sent off-site to an external composting company.

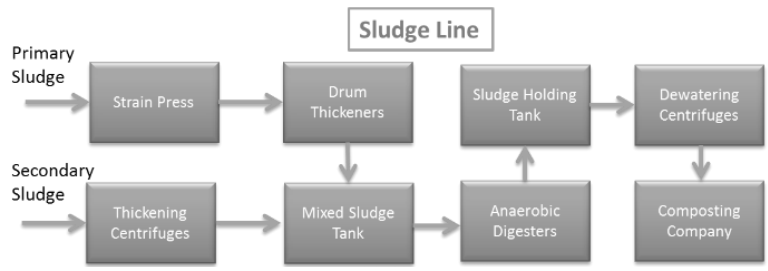

Figure 2. Plant A sludge line

Plant B has a design capacity of 50,000 PE serving a current agglomeration of 37,500 PE. The plant also accepts industrial sludge from the surrounding area as well as the sludge outputs from the smaller rural plants. The flow for the plant is shown below (Figure 3). The plant is equipped with anaerobic digesters and biogas storage facilities, but the plant operators were having difficulties running the digesters effectively and they were out of commission during the study period. The sludge outputs from the plant are sent to a sludge management company that stabilizes the sludge with lime before sending it for application to farmland.

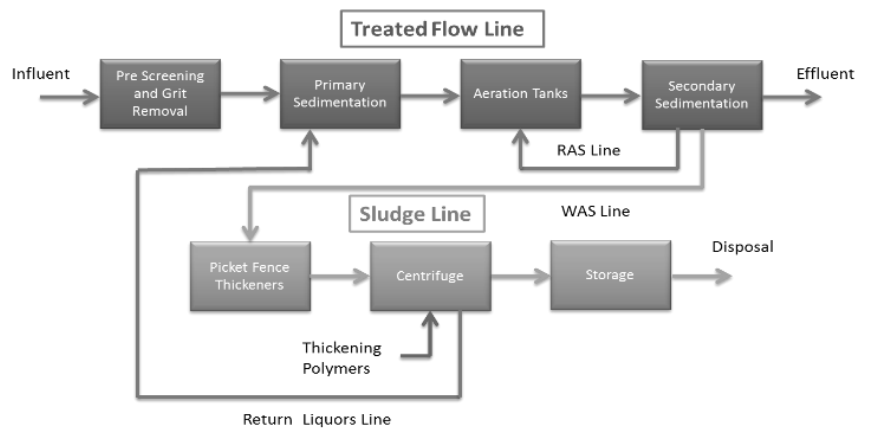

Figure 3. Plant B influent flow and sludge flow lines 


\section{DATA}

\section{Data quality}

The data quality of an LCA will ultimately determine the level of meaningfulness and transparency in a study. Direct collection and analysis of data is always the most preferred level of quality but not always the most practical or even possible. In this project a selection of data has been collected from the literature and a number of estimations have had to be made where gaps in direct, on-site data existed. Table 1 outlines the data sources used in the study. In general, the data for plant $\mathrm{A}$ is of a higher quality than that of plant B. Plant A in its current form is less than 3 years old. It has a bespoke, state-of-the-art SCADA system that monitors almost all aspects of plant operation. Sampling of influent, primary effluent and final effluent for $\mathrm{BOD}_{5}, \mathrm{COD}$ and TSS are carried out daily. Sludge outputs are recorded as well as biogas produced from Anaerobic Digestion (AD). Electricity consumption is recorded and can also be quantified at a subsystem level - inlet works, biological reactors, sludge treatment, outfall pumping and utilities have individual metering. All of the upstream data such as electricity and chemical production is supplied by PE International. Electricity and natural gas production reflects Ireland's electricity grid and natural gas mix respectively, but chemical production is based on European averages. Downstream data - energy and resource consumption data, emissions data - for the composting company used by plant A were not available; therefore the main pollutants in the sludge leaving the plant (nitrogen, phosphorus, heavy metals) were considered to end up in soil regardless of dilution post composting. The author recognises that this is a broad assumption, but a full LCA of the composting company is outside the scope of this stage of the project.

Table 1. Sources of data used in the LCA

\begin{tabular}{ccc}
\hline Site specific data & Plant A & Plant B \\
\hline Influent flow & Plant operators - measured & Based on plant \\
Effluent flow & Plant operators - measured & EPA data - measured \\
BOD, COD, TSS & Plant operators - measured & EPA data - measured \\
Total N, total P & EPA data - average & EPA data - measured \\
Influent heavy metals & EPA data - average & EPA data - measured \\
Sludge output volume & Plant operators - measured & EPA data - average \\
Sludge dry solid & Plant operators - measured & Estimated - based on plant \\
Sludge heavy metals & Literature [31] & \\
Electricity consumption & Plant operators - measured & Plant operators - measured \\
Biogas production & Plant operators - measured & N/A \\
Natural gas consumption & Plant operators - measured & N/A \\
Chemical consumption & Plant operators - measured & Estimated \\
\hline Upstream/downstream & & PE International \\
\hline Electricity production & PE International & PE International \\
Chemical production & PE International & PE International \\
Natural gas production & PE International & PE International \\
Diesel refinement & PE International &
\end{tabular}

The flow data for plant B are supplied mainly from the data collection carried out by the EPA as part of its compliance with $91 / 271$ for the year 2012. This data includes; levels of $\mathrm{BOD}_{5}, \mathrm{COD}$, TSS, TN and TP, as well as heavy metal concentrations in influent and effluent. It also includes details of sampling frequency and quality. Other data for the 
plant was estimated or taken from the literature. As with plant A, all of the upstream and downstream data such as electricity and chemical production is supplied by PE International. Both plants employ solid waste compressors to reduce volume, but neither plant could provide meaningful data for quantities of solid waste disposal.

The impact of land-use has not been included in these analyses. The issue of how to model land-use in terms of inventory and characterisation is an area of fervent debate in the LCA community [30]. Significant uncertainties exist regarding temporal and spatial variabilities. In addition to this, the lack of site-specific solid waste data meant that there would have to be broad assumptions made regarding the impact of land-use, and the author felt that this would reduce the quality of the results.

\section{RESULTS}

\section{Life cycle inventory}

The Life Cycle Inventory (LCI) is a compilation of all of the inputs and outputs of the system up to the established boundary limits. The data shown below in Table 2 are the average values of the key metrics used in the study. It would not be practical to present the full LCI due to the large volume of data. The influent pollutant concentrations at both plants are similar. Plant A experiences higher TSS, $\mathrm{BOD}_{5}$ and TP concentrations than plant $\mathrm{B}$, but lower COD and TN concentrations.

Table 2. Selection of data from the life cycle inventory

\begin{tabular}{|c|c|c|}
\hline Inputs & Plant A & Plant B \\
\hline Influent $\left[\mathrm{m}^{3} /\right.$ year] & $10,844,150$ & $4,743,605$ \\
\hline $\mathrm{BOD}_{5}[\mathrm{mg} / \mathrm{l}]$ & 184 & 175 \\
\hline COD [mg/l] & 377 & 400 \\
\hline $\mathrm{TSS}[\mathrm{mg} / \mathrm{l}]$ & 263.3 & 166 \\
\hline $\mathrm{TN}[\mathrm{mg} / \mathrm{l}]$ & 38.15 & 41.4 \\
\hline $\mathrm{TP}[\mathrm{mg} / \mathrm{l}]$ & 8.25 & 5.14 \\
\hline $\mathrm{NH}_{3}$ & 29.11 & - \\
\hline Electricity [kWh/year] & $5,299,500$ & $3,376,844$ \\
\hline Ferric chloride $\left[\mathrm{kg} / \mathrm{m}^{3}\right.$ influent $]$ & 0.008 & 0.036 \\
\hline \multicolumn{3}{|l|}{ Outputs } \\
\hline $\mathrm{BOD}_{5}[\mathrm{mg} / \mathrm{l}]$ & 5.1 & 10.97 \\
\hline $\mathrm{COD}[\mathrm{mg} / \mathrm{l}]$ & 34.8 & 32.2 \\
\hline $\mathrm{TSS}[\mathrm{mg} / \mathrm{l}]$ & 10.1 & 8.76 \\
\hline $\mathrm{TN}[\mathrm{mg} / \mathrm{l}]$ & 14.42 & 20.89 \\
\hline $\mathrm{TP}[\mathrm{mg} / \mathrm{l}]$ & 3.15 & 0.54 \\
\hline $\mathrm{NH}_{3}$ & 1.11 & 1.2 \\
\hline Sludge [kg-ds/year] & $1,047,012$ & 665,202 \\
\hline
\end{tabular}

The discharge limitations for both plants are presented in Table 3. Plant B releases its final effluent to a freshwater body and as such is subject to more stringent discharge limitations than plant A. Despite this, plant A exhibits a high level of effluent quality, and even surpasses plant $\mathrm{B}$ in $\mathrm{BOD}_{5}$ and $\mathrm{TN}$ reduction even though there is no requirement for $\mathrm{TN}$ reduction at plant $\mathrm{A}$. The effluent ammonia concentrations at plant $\mathrm{A}$ were also lower; however there were no recorded influent ammonia data for plant $\mathrm{B}$, thus, it cannot be assumed that plant $\mathrm{A}$ has a better removal efficiency of ammonia. Plant A had a lower sludge output per unit of influent treated, $0.09 \mathrm{~kg}-\mathrm{ds} / \mathrm{m}^{3}$ of influent treated compared with 
$0.14 \mathrm{~kg}-\mathrm{ds} / \mathrm{m}^{3}$ at plant B. The breakdown of energy use is discussed separately in the following section.

Table 3. Final effluent discharge limitations for both plants

\begin{tabular}{ccc}
\hline Discharge parameter & Plant A & Plant B \\
\hline $\mathrm{pH}$ & - & $6-9$ \\
Temperature & - & $25^{\circ} \mathrm{C}(\mathrm{max})$ \\
cBOD & $25 \mathrm{mg} / \mathrm{l}$ & $13 \mathrm{mg} / 1$ \\
COD & $125 \mathrm{mg} / 1$ & $100 \mathrm{mg} / 1$ \\
TSS & $35 \mathrm{mg} / 1$ & $35 \mathrm{mg} / 1$ \\
Total Nitrogen (TN) & - & $15 \mathrm{mg} / 1$ \\
Total Phosphorous (TP) & - & $1 \mathrm{mg} / 1$ \\
Ammonia & - & $3 \mathrm{mg} / 1$ \\
\hline
\end{tabular}

\section{Energy}

Plant A consumes $36 \mathrm{kWh} / \mathrm{PE}$ year, $60 \%$ of which is supplied by the national electrical grid and $40 \%$ is generated by the Combined Heat and Power (CHP) plant. Of the $40 \%$ of power produced by the CHP plant, $75 \%$ of the energy comes from natural gas and the remaining $25 \%$ is generated from biogas produced by anaerobic digestion of the sludge, which provides $10 \%$ of the total energy consumption of the plant. Plant B consumes $52 \mathrm{kWh} / \mathrm{PE}$ year, all of which comes from the national grid. Figure 4 shows the percentage consumption per process of both plants. Data for plant B were limited to metering of the biological reactors and the total plant consumption. The biological reactors at plant $\mathrm{B}$ account for $75 \%$ of the total plant energy consumption. The biological reactors at plant A account for just 30\% of energy consumption. Sludge treatment was the largest consumer of energy at plant $\mathrm{A}$ at $37 \%$. However sludge treatment at plant A consists of an extensive series of thickening and dewatering processes, a vast odour extraction system, as well as two mesophilic anaerobic digesters. The inlet works which includes pre-screening, grit removal and primary sedimentation account for $26 \%$ of the total energy.

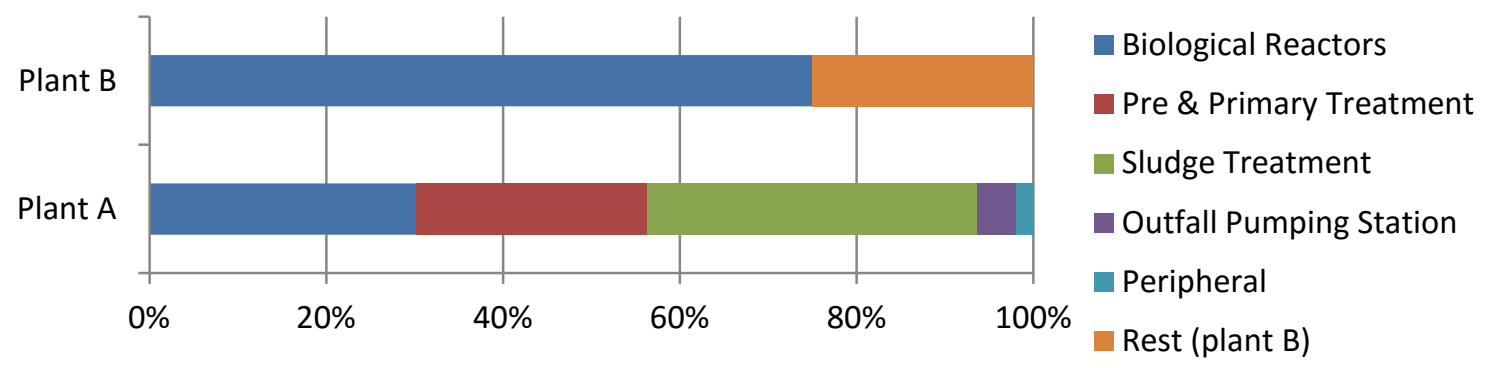

Figure 4. Process breakdown of energy expenditure. The biological reactors in plant B account for $75 \%$ of total energy consumed. Sludge treatment consumes the most energy at plant A with $37 \%$ of the total

\section{LIFE CYCLE IMPACT ASSESSMENT}

\section{Methodology}

The format used in this study follows the procedure set out by the ISO 14040 series of standards [32-35], and references guidelines on the standards published by Guinée et al. [36]. The software chosen for the project was $\mathrm{GaBi}$ 6.0. The GaBi database provided by PE International contains inventory data for many of the WWTPs upstream processes 
such as energy and chemical production. The Life Cycle Impact Assessment (LCIA) methodology used in the study is the CML (Centre for Environmental Science) 2001 (Nov. 10) which is compliant with the ISO 14040 series, and has been adopted by authors of similar studies [27]. The impact categories defined in the methodology are presented in Table 4. Once the impact categories have been defined the next phase of the LCIA is classification, whereby system inputs and outputs that have been compiled in the LCI are assigned qualitatively to one or more of the impact categories. Following this, the characterisation phase calculates the magnitude of a substance in an impact category based on an equivalency factor relative to a baseline substance for that category. For example, COD in the final effluent discharge is assigned to eutrophication. The baseline substance for eutrophication is $\mathrm{PO}_{4}{ }^{3-}$ (phosphate) and has a value of 1 . The equivalency factor value of COD is 0.022 [8], therefore, every $1 \mathrm{~g}$ of COD is equivalent to $0.022 \mathrm{~g}$ of phosphate in the CML eutrophication impact category.

This method allows for aggregation of all substances in a given category into a single score or indicator result (eq. 1) [36], where $i$ is the type of substance, $m_{i}$ is the magnitude and $e f_{i}$ is the equivalency factor for that substance:

$$
\text { indicator result }=\sum_{i} m_{i} e f_{i}
$$

Table 4. CML 2001 life cycle impact assessment categories

\begin{tabular}{|c|c|c|}
\hline Impact category & Abbreviation & Units \\
\hline Global warming potential & GWP & {$\left[\mathrm{kg} \mathrm{CO} \mathrm{CO}_{2} \mathrm{eq}\right]$} \\
\hline Acidification potential & AP & {$\left[\mathrm{kg} \mathrm{SO}_{2} \mathrm{eq}\right]$} \\
\hline Eutrophication potential & EP & {$\left[\mathrm{kg} \mathrm{PO}_{4}{ }^{3-} \mathrm{eq}\right]$} \\
\hline Ozone depletion potential & ODP, steady state & {$[\mathrm{kg} \mathrm{R} 11 \mathrm{eq}]^{\S}$} \\
\hline Photochemical oxidation potential & PCOP & {$\left[\mathrm{kg} \mathrm{C}_{2} \mathrm{H}_{6} \mathrm{eq}\right]$} \\
\hline \multicolumn{3}{|l|}{ Ecotoxicity } \\
\hline Freshwater aquatic & FAETP inf. & \\
\hline Terrestrial & TETP inf. & {$\left[\mathrm{kg} \mathrm{C}_{6} \mathrm{H}_{4} \mathrm{Cl}_{2}\right.$ eq] } \\
\hline Marine aquatic & MAETP inf. & \\
\hline Human toxicity potential & HTP inf. & $\mathrm{kg} \mathrm{C}_{6} \mathrm{H}_{4} \mathrm{Cl}_{2}$ eq] \\
\hline Abiotic depletion elements & ADPe & {$[\mathrm{kg} \mathrm{Sb}$ eq] } \\
\hline Abiotic depletion fossil & ADPf & {$[\mathrm{MJ}]$} \\
\hline
\end{tabular}

\section{Impact category loading}

Figure 5 and Figure 6 present the environmental loading of both plants. Ozone depletion potential (Figure 6) is presented seperately due to the large difference in loading magnitude when compared with the other impact categories. The outputs have been normalised with 2013 Western Europe normalisation factors that yield dimensionless weighted quantities. This allows easier interpretation of results, as illustrated by Ramos et al. [37]. It should be noted that the vertical axis in Figure 5 is in logarithmic scale and therefore differences in outputs of some categories are significant. The percentage differences are presented in Table 5.

In general, plant A performs better across all categories. Global impact categories such as MAETP, GWP, AP, and ADPf are heavily influenced by energy consumption.

\footnotetext{
$\S$ The refrigerant R11 is a chlorofluorocarbon (CFC)
} 
Plant A requires only $40 \%$ of the energy that plant B requires for biological aeration and this is reflected in the percentage difference in loading in these categories. This suggests that there are economies of scale to be achieved in aeration energy requirements as reported by Burton (Figure 7) [38]. Sludge disposal accounts for the greater percentage of loading in MAETP, FAETP and TETP. Final effluent discharge and sludge disposal are the largest contributors to eutrophication, and ODP is dominated by ferric chloride production. The following sections discuss the loadings of each impact category individually.

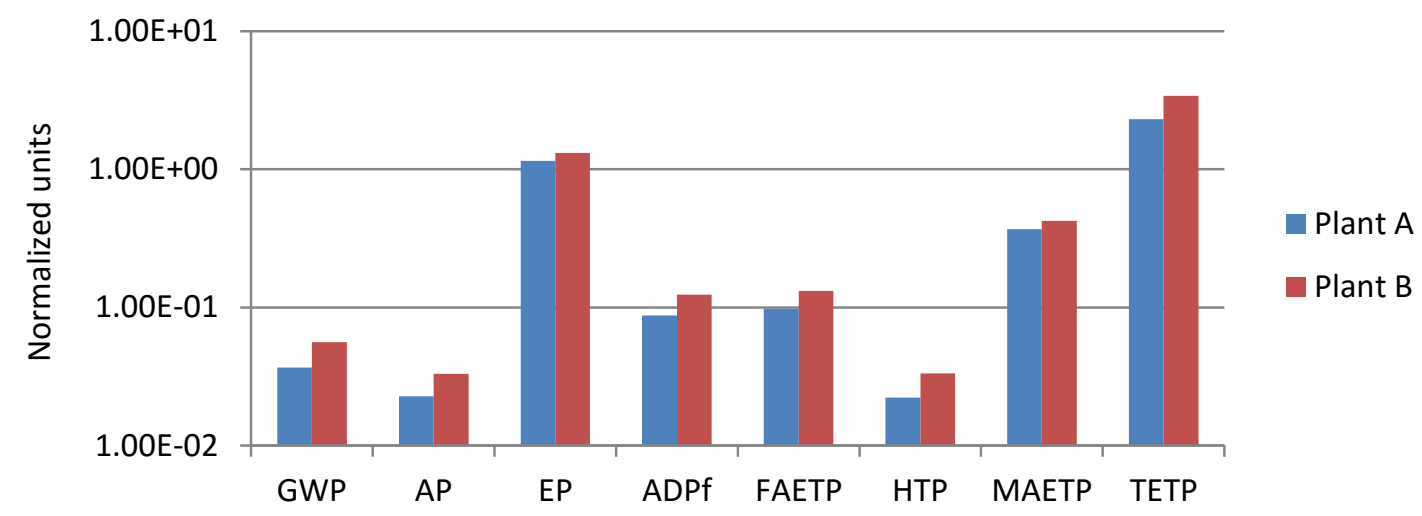

Figure 5. Normalized results per PE-year $\left(\times 10^{10}\right)$

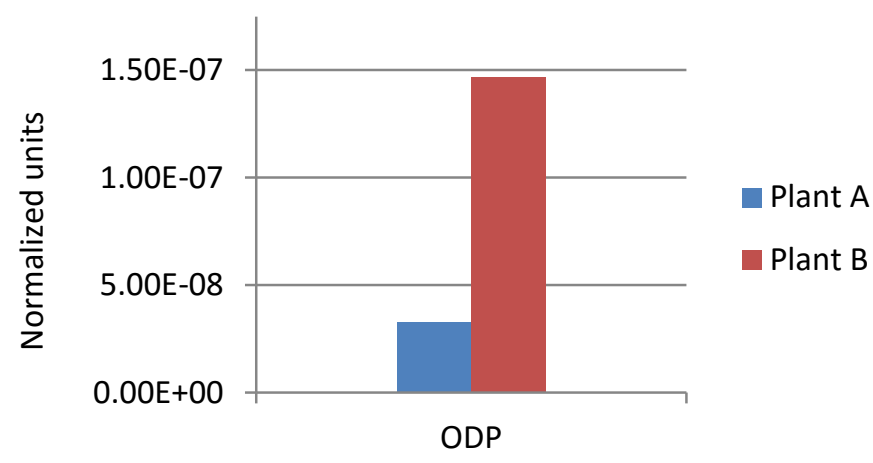

Figure 6. Normalized results of ozone depletion potential per PE-year $\left(\times 10^{10}\right)$

Table 5. Dimensionless normalised impact category values $\left(\times 10^{10}\right)$ and percentage difference between plants (plant $B$ used as reference)

\begin{tabular}{cccc}
\hline Impact categories & Plant A & Plant B & $\begin{array}{c}\text { Percentage difference in } \\
\text { impact loading [\%] }\end{array}$ \\
\hline ADPf & 0.0875 & 0.123 & 29.25 \\
AP & 0.022 & 0.033 & 31.48 \\
EP & 1.150 & 1.307 & 12.06 \\
FAETP & 0.097 & 0.131 & 25.90 \\
GWP 100 & 0.036 & 0.056 & 34.52 \\
HTP & 0.022 & 0.033 & 33.24 \\
MAETP & 0.369 & 0.422 & 12.70 \\
ODP & $3.27 \times 10^{-8}$ & $1.47 \times 10^{-7}$ & 77.6 \\
TETP & 2.30 & 3.40 & 32.45 \\
\hline
\end{tabular}




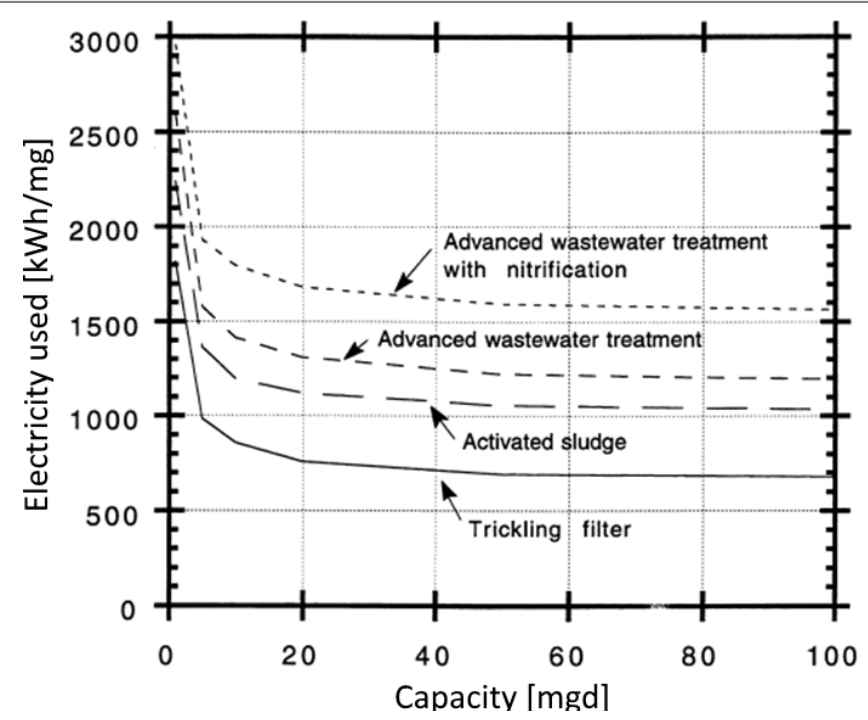

Figure 7. Energy consumption for different treatment processes [38]

Eutrophication. The eutrophication impact from plant $\mathrm{A}$ is dominated by the output of the final effluent (Figure 8). Plant A discharges its final effluent into coastal waters and does not have the TN and TP reduction requirements of plant $\mathrm{B}$. Plant $\mathrm{A}$ also has higher discharge limits for $\mathrm{BOD}_{5}(25 \mathrm{mg} / \mathrm{l})$ and COD $(125 \mathrm{mg} / \mathrm{l})$ compared with $13 \mathrm{mg} / \mathrm{l}$ and $100 \mathrm{mg} / \mathrm{l}$ respectively for plant B. This is reflected in the EP outputs of both plants where the more stringent discharge requirements at plant B have resulted in just over $20 \%$ of the total EP output coming from the final effluent discharge, compared with close to $100 \%$ from plant A. Phosphorus contribution to eutrophication is 140 times that of COD [8], thus small differences in phosphorus levels in final effluent will have a large effect on eutrophication, when compared with changes in $\mathrm{BOD}_{5} / \mathrm{COD}$ levels. The concentration of phosphorus in the plant A final effluent is almost six times that of plant B. Nitrification/denitrification requirements at plant B can increase Solids Retention Time (SRT) values which reduce secondary sludge yields due to endogenous respiration [39]. However, when comparing the sludge outputs of both plants, any gains obtained from the reduced sludge yield at plant $B$ due to extended SRT are offset by the lack of AD, from which plant A benefits. Furthermore, the total sludge output volume per PE increases compared with plant A. Despite the large percentage difference in the contributing sources to eutrophication, the overall difference between the plants is $<13 \%$.

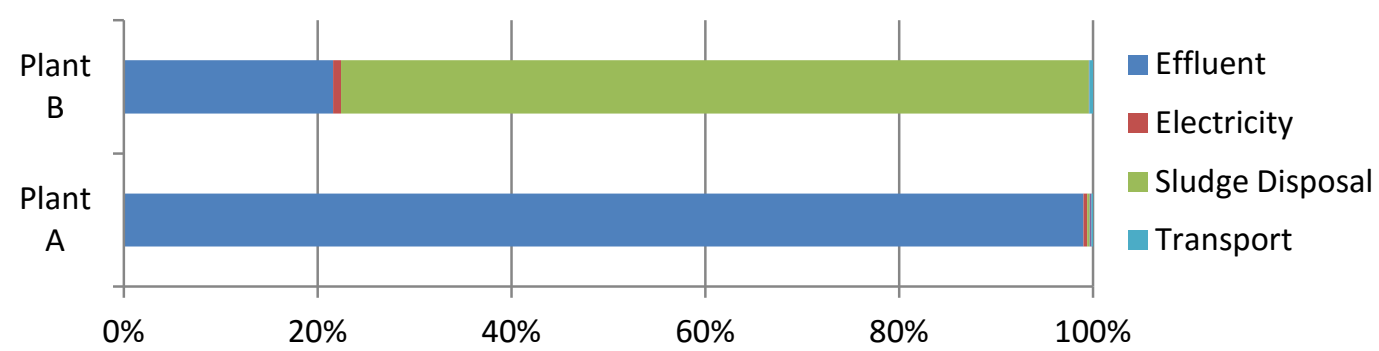

Figure 8 . The contribution to eutrophication by plant $\mathrm{A}$ is dominated by the final effluent discharge while almost $80 \%$ of the contribution of plant B comes from sludge disposal

Global warming potential. The contribution to GWP from both plants is dominated by electrical energy production (Figure 9). Of the total contribution to GWP loading at plant A, 73\% can be attributed to electricity consumption while ferric chloride production 
accounts for $22 \%$. The remainder of the loading comes from natural gas production and an aggregated total for sludge and chemical transport. The plant B electricity consumption accounts for almost $68 \%$ of the total contribution to GWP. Lime production is the second largest contributor at $24 \%$ while the remainder is made up from Ferric chloride production and transportation of chemicals and sludge.

The energy usage at both plants accounts for over $75 \%$ of the overall contribution to the GWP impact. This can be attributed to the heavy dependence on fossil fuel in the Irish electrical grid mix (Figure 10). Natural gas, hard coal, peat and heavy fuel oil make up almost $82 \%$ of the electrical grid mix in Ireland [40].

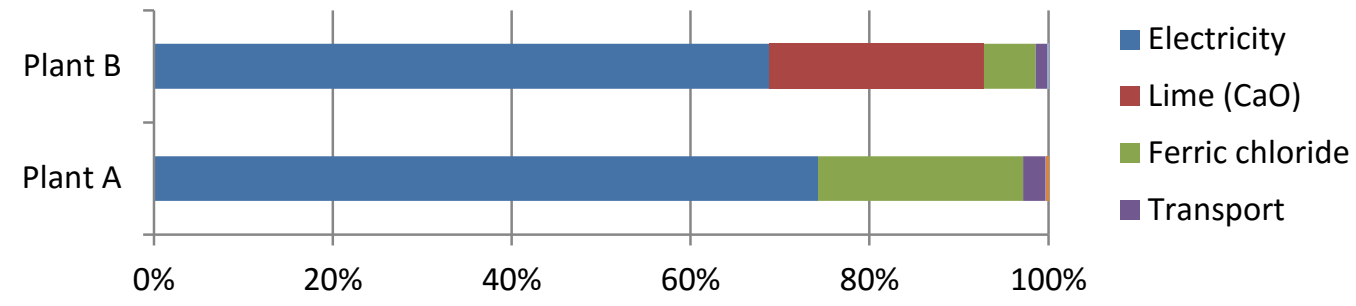

Figure 9. GWP 100 impact for both plants is dominated by electricity production

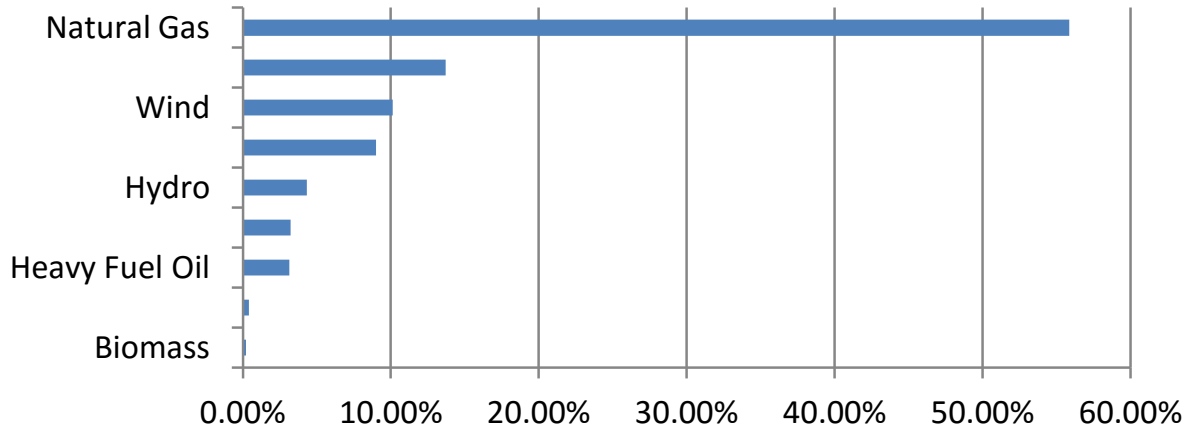

Figure 10. Ireland's electricity grid mix. Almost $82 \%$ of the electricity grid mix in Ireland is fossil fuel based. It is for this reason that the energy consumption at both WWTPs is the main contributor to GWP

Acidification potential. Acidification potential is dominated by the impact of energy production, accounting for $>60 \%$ of the contribution for plant A and $78 \%$ for plant B (Figure 11). Ferric chloride production accounts for $28 \%$ of AP at plant A, while transport of sludge and chemicals was the next largest contributor at plant B.

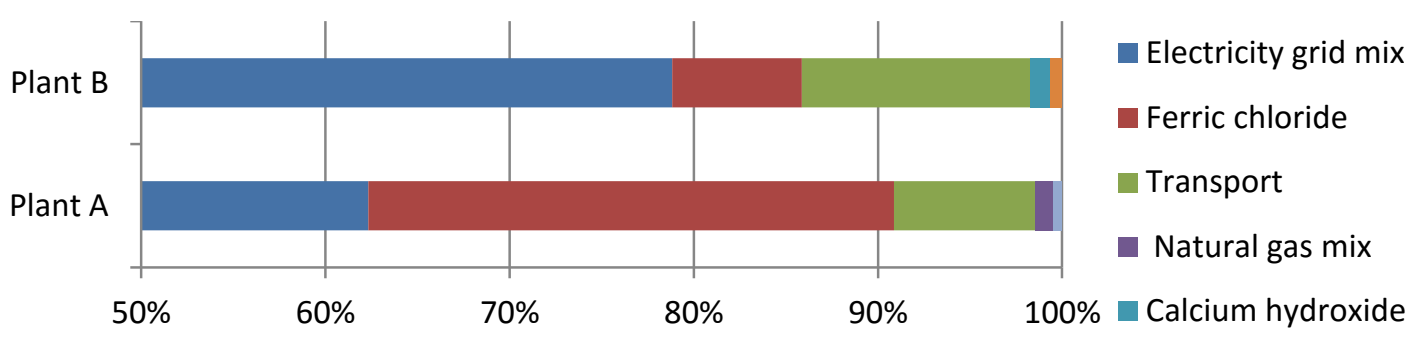

Figure 11. Acidification potential for both plants is dominated by energy generation

Freshwater ecotoxicity potential. The FAETP impacts for both plant A and plant B are dominated by sludge application to land (Figure 12). The effluent discharge from plant B contributes $12 \%$ of the overall loading in this category. 


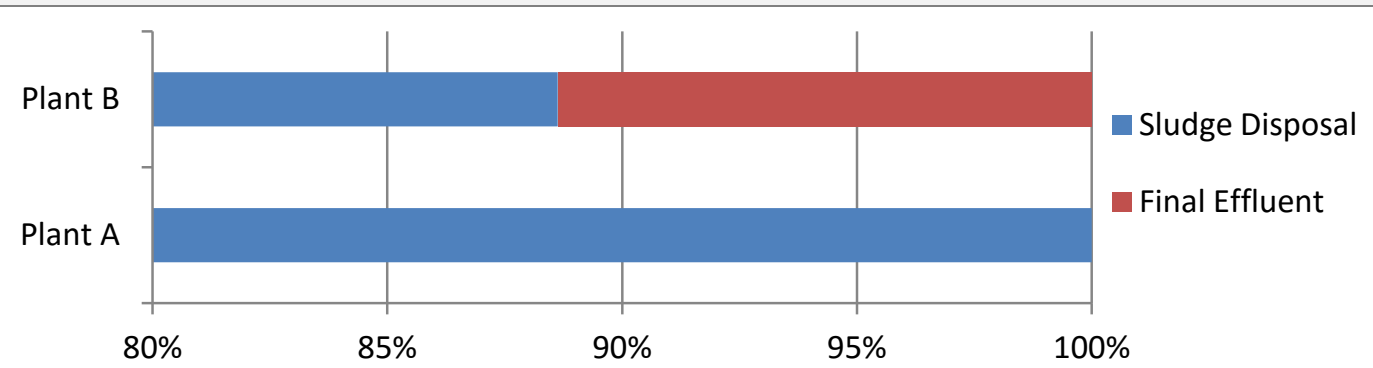

Figure 12. Freshwater aquatic ecotoxicity potential

Marine aquatic ecotoxicity potential. Over $40 \%$ of the MAETP output of plant A comes from final effluent discharge, over 33\% is due to sludge disposal. Sludge disposal accounts for over $55 \%$ of the loading in plant B. Electricity production is the second largest contributor to this category with almost $30 \%$ of the total impact (Figure 13).

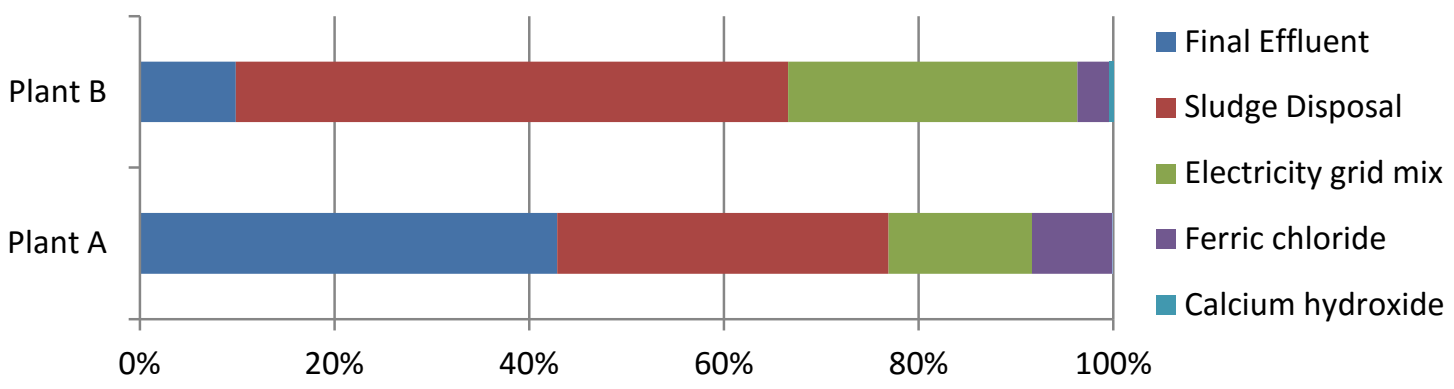

Figure 13. Marine aquatic ecotoxicity potential

Human toxicity potential. HTP is dominated in both plants by sludge disposal with only small contributions from other processes such as electrical and chemical production (Figure 14).

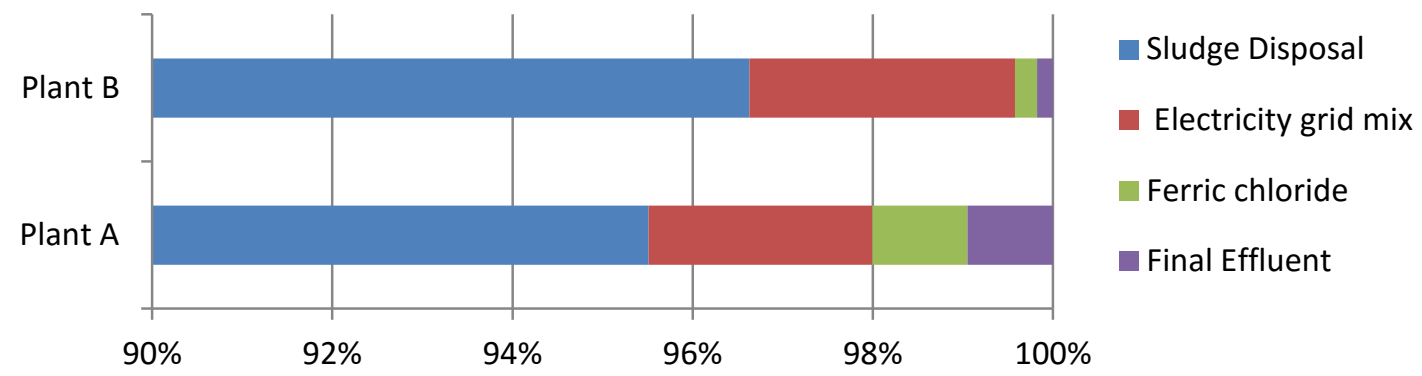

Figure 14. Human toxicity potential

Terrestrial ecotoxicity. Sludge disposal accounts for almost $100 \%$ of the TETP impact in both plants (Figure 15). The digested sludge output from plant $\mathrm{A}$ is $9.7 \mathrm{~kg}$-ds/PE year (kilogrammes of dry solids per person equivalence year) at a solid concentration of $22 \%$. The sludge is sent to a composting company $175 \mathrm{~km}$ from the plant where it is further treated. The undigested sludge output from plant B is $18.6 \mathrm{~kg}$-ds/PE year at a solid concentration of $8 \%$. The sludge is estimated to travel an average distance of $50 \mathrm{~km}$ from the plant for direct application to farmland. Direct application to farmland has been found to be the least favourable option of sludge disposal in several LCA studies carried out to examine the environmental loading for several disposal methods [23, 24]. 


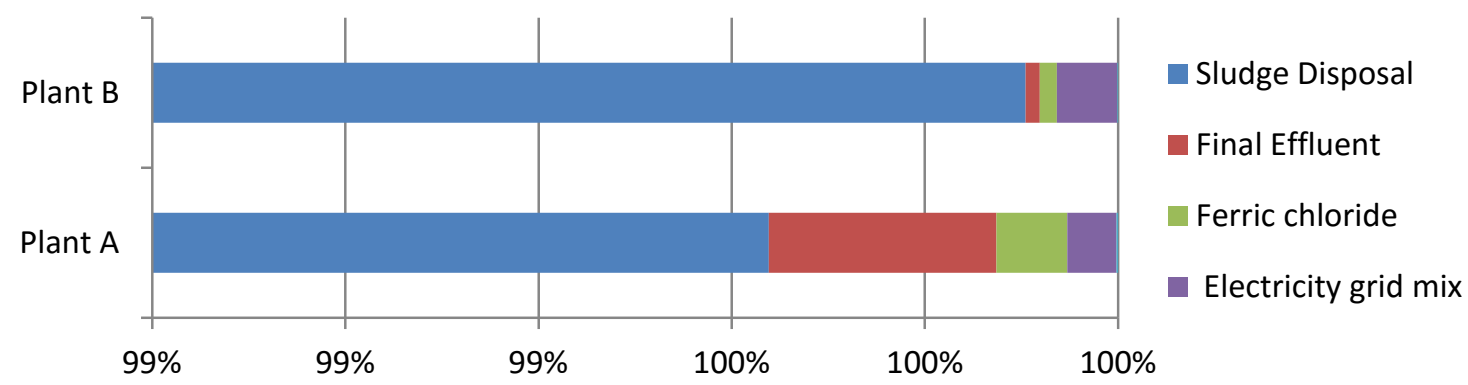

Figure 15. Terrestrial ecotoxicity

Ozone depletion potential. Ferric chloride production accounts for over $90 \%$ of the ODP impact in both plants with minimal contributions from electrical and other chemical production (Figure 16). Plant A outputs $2.01 \times 10^{-9} \mathrm{~kg}$ of R11-equiv/PE year (kilograms of chlorofluorocarbon equivalent per person equivalent year). Ferric chloride production accounts for over $98 \%$ of this total with less than $2 \%$ contribution from electricity production. The plant B output to ODP is $9.88 \times 10^{-9} \mathrm{~kg}$ of R11-equiv/PE year. Ferric chloride production accounts for $<92 \%$ of this total and the contribution from electricity production increases to $8 \%$. The study carried out by Hospido et al. [27] found that chemical production contributed almost half of the loading to this category with the remainder being attributed to electricity production. The difference here can be attributed mainly to the difference in both countries electricity grid mix. The Spanish electrical grid mix contributes over 100 times more to ODP than the Irish grid, thus decreasing the percentage contribution of chemical production in the Spanish scenario. The difference between the two Irish plants could be attributed in part to the economies of scale in terms of $\mathrm{kWh} / \mathrm{PE}$ Plant B uses $40 \%$ more energy per PE than plant A, thus increasing the percentage contribution of electricity production to the impact category.

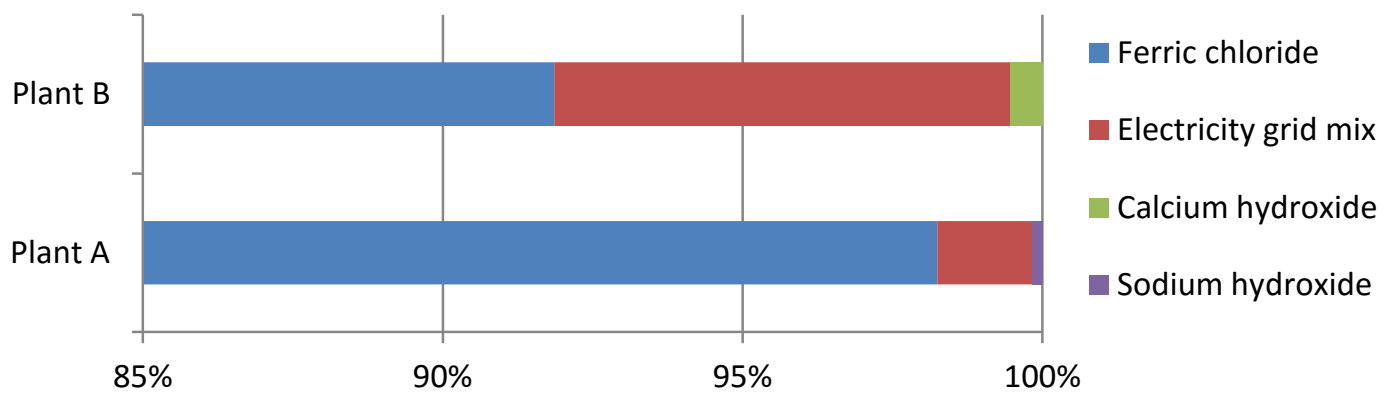

Figure 16. The ozone depletion impact is dominated by ferric chloride production which accounts for over $90 \%$ of the loading at both plants

Abiotic depletion potential (fossil). The CML methodology for ADP distinguishes between ADP fossil and ADP elements. ADP elements describes the depletion of the total natural reserves of the elements without regard for their functionality, while ADP fossil is defined by the energy content of the fossil fuels measured in MJ. As energy consumption and production is central to this study, it has been decided that ADP fossil is the most relevant of the two impact categories. Electricity production is the main source of resource depletion. It accounts for over $60 \%$ of the output for plant A and over $80 \%$ of the output for plant B. Ferric chloride production is the next largest contributor for plant A with almost $20 \%$, whilst making up $<5 \%$ of the contribution for plant B. The diesel refinery mix accounted for $15 \%$ of the plant A output (Figure 17). 


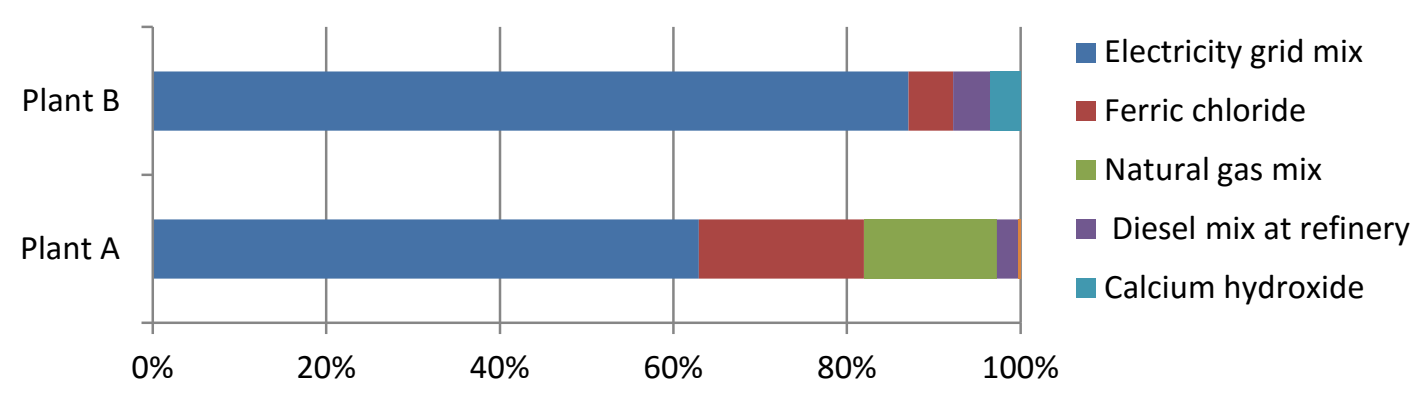

Figure 17. Abiotic depletion potential of both plants

\section{DISCUSSION}

When considering the environmental impact associated with waste water treatment the main focus is generally on eutrophication caused by the final effluent. However, the 91/271 directive has established a set of acceptable limits for pollutant concentrations in final effluent for $\mathrm{BOD}_{5}, \mathrm{COD}$ and TSS, as well as nutrient limits of phosphorus and nitrogen. If it is understood and accepted by the scientific community that these limits represent a sustainable, non-destructive level of eutrophication, then the primary focus should no longer be on the quality of the final effluent, but more on the impact that results from achieving this effluent quality.

This study found that there were two main contributors to environmental loading outside of final effluent discharge: the energy that goes into treating the influent and the sludge disposal. The electricity grid mix in Ireland contributes heavily to global impact categories such as MAETP, GWP, AP and ADPf, whereas sludge disposal contributes mainly to the ecotoxicity categories. Anaerobic digestion creates a link between the energy that is consumed during the treatment process and the embedded energy in the sludge. Plant A employs anaerobic digestion and this serves a number of purposes:

- $\mathrm{AD}$ reclaims a significant amount of energy that can be fed back into the operation of the plant, reducing aerial emissions associated with electricity generation;

- $\mathrm{AD}$ reduces the volume of sludge leaving the plant which reduces transport emissions and fuel consumption. This can be significant when the sludge has to travel long distances to its final destination as is the case with plant A;

- AD stabilises sludge which reduces the emissions associated with lime production, and reduces resource depletion.

It is without doubt that anaerobic digestion is a key process in wastewater treatment as it reduces the output of two of the main contributors to the overall environmental impact. In terms of what happens after the sludge is digested, there needs to be a definitive solution on how best to dispose of the sludge. The literature is filled with conflicting opinions on the topic of sludge disposal. However, most studies would agree that land-filling and direct application to farmland are the least favoured options.

\section{CONCLUSIONS}

The purpose of the study was to assess the environmental performance of two WWTPs in Ireland. Life cycle assessment was the analytical tool used. The plants that were chosen for the study varied in scale and location. In relation to the latter, the main focus was on the differences in discharge limits. It has been shown that more stringent discharge limits will reduce eutrophic environmental loading, but the extra energy and materials that are consumed reaching the higher quality final of effluent can increase environmental loading in several other impact categories. Lower BOD limits typically 
result in an increase in aeration energy requirements and this in turn increases loading in impact categories that are dominated by contributions from energy production such as MAETP, ADPf, GWP and AP. Phosphorous reduction requirements increase ferric chloride consumption, and thus production, which increases environmental loading in a number of impact categories such as ODP, GWP and MAETP.

Investigations of the effect of variation in scale proved difficult because of differences in system configuration and the fact that one plant was successfully running its anaerobic digesters while the other was not. The plant with the functioning digesters was reclaiming some energy and reducing sludge outputs. This has the effect of reducing the loading in several impact categories. However, even if the energy reclaimed from anaerobic digestion were excluded, there would still be a significant difference in energy consumption between plants. What could be concluded in relation to scale was that there were significant economies of scale to be achieved in aeration energy consumed during secondary treatment.

It would be prudent to research further, and in greater detail, the exact sources of any energy and resource savings that could be made. There are other areas of plants operation that are also worthy of investigation such as plant management, flow monitoring and system configuration. Indeed, there is an abundance of research opportunities in this field. One further point of note in relation to this research is that because the UWWTD is pan-European legislation, the research could be expanded to compare energy and resource efficiency of water and wastewater treatment systems across the continent. Life cycle assessment is growing in popularity, and is seen by many as a suitable analytical tool for environmental profiling of existing plants, and as a decision support mechanism for future development of more environmentally sustainable wastewater treatment systems.

\section{REFERENCES}

1. European Commission, Council Directive: Concerning Urban Waste Water Treatment (91/271/EEC), Brussels, 1991.

2. Henze, M., Wastewater Treatment: Biological and Chemical Processes, $2^{\text {nd }}$ ed., Springer, Berlin, New York, 1997, http://dx.doi.org/10.1007/978-3-662-22605-6

3. Jones, R. N., An Environmental Risk Assessment/management Framework for Climate Change Impact Assessments, Nat. Hazards, Vol. 23, No. 2-3, pp 197-230, 2001, http://dx.doi.org/10.1023/A:1011148019213

4. Rosen, M. A., Exergy, Can. Cons. Eng., Vol. 46, No. 2, pp 25-28, 2005.

5. Crane, P., Scott, D. S. and Rosen, M. A., Exergy of Emissions as a Measure of Potential for Environmental Impact (Veziro, T. N., Takahashi, P. K., eds.), Hydrogen Energy Progress VIII, Proceedings, $8^{\text {th }}$ World Hydrogen Energy Conf., 2012.

6. Ayres, R. U., Ayres, L. W. and Martinás, K., Exergy, Waste Accounting, and Life-cycle Analysis, Energy, Vol. 23, No. 5, pp 355-363, 1998, http://dx.doi.org/10.1016/S0360-5442(97)00076-5

7. Gaudreau, K., Fraser, R. A. and Murphy, S., The Characteristics of the Exergy Reference Environment and its Implications for Sustainability-Based Decision-Making, Energies, Vol. 5, pp 2197-2213, 2012, http://dx.doi.org/10.3390/en5072197

8. Tillman, A. M. and Baumann, H., The Hitch Hiker's Guide to LCA, 1:7 ed., Vol. 1, Holmsbergs, Sweden, 543 p, 2004.

9. Jensen, A. A., Hoffman, L., Moller, T. B. and Schmidt, A., Life Cycle Assessment: A Guide to Approaches, Experiences and Information Sources, Environmental Issue Series, pp 53-56, 1997. 
10. Roeleveld, P. J., Klapwijk, A., Eggels, P. G., Rulkens, W. H. and van Starkenburg, W., Sustainability of Municipal Waste Water Treatment, Advanced Wastewater Treatment: Nutrient Removal and Anaerobic Processes Selected Proceedings of the IAWQ International Conference on Advanced Wastewater Treatment: Nutrient Removal and Anaerobic Processes (AQUATECH 96), Water Science and Technology, Vol. 35, No. 10, pp 221-228, 1997, http://dx.doi.org/10.1016/S0273-1223(97)00199-6

11. Corominas, L., Foley, J., Guest, J. S., Hospido, A., Larsen, H. F., Morera, S. and Shaw, A., Life Cycle Assessment Applied to Wastewater Treatment: State of the Art, Water Res., Vol. 47, No. 15, pp 5480-5492, 2013, http://dx.doi.org/10.1016/j. watres.2013.06.049

12. Tillman, A., Svingby, M. and Lundstrom, H., Life Cycle Assessment of Municipal Waste Water Systems, The International Journal of Life Cycle Assessment, Vol. 3, No. 3, pp. 145-157, 1998, http://dx.doi.org/10.1007/BF02978823

13. Lundin, M., Bengtsson, M. and Sverker, M., Life Cycle Assessment of Wastewater Systems: Influence of System Boundaries and Scale on Calculated Environmental Loads, Environ. Sci. Technol., Vol. 34, No. 1, pp 180-186, 2000, http://dx.doi.org/10.1021/es990003f

14. Vidal, N., Poch, M., Martí, E. and Rodríguez-Roda, I., Evaluation of the Environmental Implications to Include Structural Changes in a Wastewater Treatment Plant, Journal of Chemical Technology \& Biotechnology, Vol. 77, No. 11, pp 1206-1211, 2002, http://dx.doi.org/10.1002/jctb.674

15. Kalbar, P. P., Karmakar, S. and Asolekar, S. R., Assessment of Wastewater Treatment Technologies: Life Cycle Approach, Water and Environment Journal, Vol. 27, No. 2, pp 261-268, 2013, http://dx.doi.org/10.1111/wej.12006

16. Gallego, A., Hospido, A., Moreira, M. T. and Feijoo, G., Environmental Performance of Wastewater Treatment Plants for Small Populations, Resour. Conserv. Recycling, Vol. 52, No. 6, pp 931-940, 2008, http://dx.doi.org/10.1016/j.resconrec.2008.02.001

17. Pasqualino, J. C., Meneses, M. and Castells, F., Life Cycle Assessment of Urban Wastewater Reclamation and Reuse Alternatives, J. Ind. Ecol., Vol. 15, No. 1, pp 49-63, 2011, http://dx.doi.org/10.1111/j.1530-9290.2010.00293.x

18. Roeleveld, P., Klapwijk, A., Eggels, P., Rulkens, W. and Van Starkenburg, W., Sustainability of Municipal Waste Water Treatment, Water Science and Technology, Vol. 35, No. 10, pp 221-228, 1997, http://dx.doi.org/10.1016/S0273-1223(97)00199-6

19. René Itten, et al., Life Cycle Inventories of Electricity Mixes and Grid, http://www.esu-services.ch/fileadmin/download/publicLCI/itten-2012-electricity-mi x.pdf, [Accessed: 03-October-2015]

20. Aubain, P., Gazzo, A., LeMoux, J., Mugnier, E., Brunet, H. and Landrea, B., Disposal and Recycling Routes for Sewage Sludge, European Commission, Vol. 22, pp 16-17, 2002.

21. Hultman, B., Levlin, E. and Stark, K., Swedish Debate on Sludge Handling, Proceedings of a Polish - Swedish Seminar on Sustainable Municipal Sludge and Solid Waste Handling, Krakow, 2000.

22. Pasqualino, J. C., Meneses, M., Abella, M. and Castells, F., LCA as a Decision Support Tool for the Environmental Improvement of the Operation of a Municipal Wastewater Treatment Plant, Environ. Sci. Technol., Vol. 43, No. 9, pp 3300-3307, 2009, http://dx.doi.org/10.1021/es802056r

23. Houillon, G. and Jolliet, O., Life Cycle Assessment of Processes for the Treatment of Wastewater Urban Sludge: Energy and Global Warming Analysis, Environmental Assessments and Waste Management, J. Clean. Prod., Vol. 13, No. 3, pp 287-299, 2005, http://dx.doi.org/10.1016/j.jclepro.2004.02.022 
24. Lundin, M., Olofsson, M., Pettersson, G. J. and Zetterlund, H., Environmental and Economic Assessment of Sewage Sludge Handling Options, Resour. Conserv. Recycling, Vol. 41, No. 4, pp 255-278, 2004, http://dx.doi.org/10.1016/j.resconrec.2003.10.006

25. Suh, Y. and Rousseaux, P., Considerations in Life Cycle Inventory Analysis of Municipal Wastewater Treatment Systems, Oral Presentation at COST 624 WG Meeting, Bologna, Italy, 2001.

26. Kelessidis, A. and Stasinakis, A. S., Comparative Study of the Methods used for Treatment and Final Disposal of Sewage Sludge in European Countries, Waste Man., Vol. 32, No. 6, pp 1186-1195, 2012, http://dx.doi.org/10.1016/j.wasman.2012.01.012

27. Hospido, A., Moreira, M. and Feijoo, G., A Comparison of Municipal Wastewater Treatment Plants for Big Centres of Population in Galicia (Spain), Int. J. of Life Cycle Assess., Vol. 13, No. 1, pp 57-64, 2008, http://dx.doi.org/10.1007/s11367-007-0314-8

28. Hospido, A., Moreira, M., Fernandez-Couto, M. and Feijoo, G., Environmental Performance of a Municipal Wastewater Treatment Plant, Int. J. of Life Cycle Assess., Vol. 9, No. 4, pp 261-271, 2004, http://dx.doi.org/10.1007/BF02978602

29. Renou, S., Thomas, J. S., Aoustin, E. and Pons, M. N., Influence of Impact Assessment Methods in Wastewater Treatment LCA, J. Clean. Prod., Vol. 16, No. 10, pp 1098-1105, 2008, http://dx.doi.org/10.1016/j.jclepro.2007.06.003

30. Heijungs, R., Guinée, J. and Huppes, G., Impact Categories for Natural Resources and Land Use, CML Report, Vol. 138, 1997.

31. European Commission, Pollutants in Urban Waste Water and Sewage Sludge, Brussels, 2001.

32. International Standard Organization, ISO 14040: Environmental Management-Life Cycle Assessment-Principles and Framework, 1997.

33. International Standards Organization, ISO 14041: Environmental Management-Life Cycle Assessment-Goal and Scope Definition and Inventory Analysis, ISO, 1998.

34. International Standards Organization, 14042: Environmental Management - Life Cycle Assessment - Life Cycle Impact Assessment, Brussels: International Organisation for Standardisation, 2000.

35. Lecouls, H., ISO 14043: Environmental Management, Lifecycle Assessment, Life Cycle Interpretation, Int. J. Life Cycle Assess., 254 p, 1999.

36. Guinée, J. B., Gorrée, M., Huppes, G., Klein, R. and De Koning, A., et al., Handbook on Life Cycle Assessment - Operational Guide to the ISO Standards, Vol. 7, Kluwer Academic Publishers, pp 51-55, 2001.

37. Dominguez-Ramos, A., Chavan, K., García, V., Jimeno, G., Albo, J., Marathe, K. V., Yadav, G. D. and Irabien, A., Arsenic Removal from Natural Waters by Adsorption or Ion Exchange: An Environmental Sustainability Assessment, Ind. Eng. Chem. Res., Vol. 53, No. 49, pp 18920-18927, 2014, http://dx.doi.org/10.1021/ie4044345

38. Burton, F. L., Water and Wastewater Industries: Characteristics and Energy Management Opportunities, CEC Report 106941, Electrical Power Research Institute, St. Louis, MO, 1996.

39. Metcalf and Eddy, Wastewater Engineering: Treatment and Reuse, $4^{\text {th }}$ ed., McGraw-Hill, New York, United States, 2002.

40. Howley, M., Dennehy, E., Holland, M. and O Gallachoir, B., Energy in Ireland: Key Statistics 2012, 2012. 